\title{
Características da Carcaça de Cordeiros Alimentados com Dietas Contendo Grãos de Milho Conservados em Diferentes Formas ${ }^{1}$
}

\author{
Wagner dos Reis ${ }^{2}$, Clóves Cabreira Jobim ${ }^{3^{*}}$, Francisco A. F. Macedo ${ }^{3}$, Elias Nunes Martins ${ }^{3^{*}}$, \\ Ulysses Cecato ${ }^{*}$
}

\begin{abstract}
RESUMO - O objetivo do presente estudo foi avaliar o uso de grãos de milho em diferentes formas (grãos secos, silagem de grãos úmidos, grãos hidratados e ensilados) na dieta de cordeiros confinados, e seus possíveis efeitos sobre a qualidade da carcaça, compreendendo avaliações quantitativas e qualitativas. Vinte cordeiros machos cruza Bergamácia x Corriedade foram utilizados. Os animais foram confinados, distribuídos em cinco tratamentos, que consistiram de diferentes relações grãos de milho secos:silagem de grãos úmidos ou de milho hidratado $(0: 100,50: 50,100: 0)$. Não houve efeito dos tratamentos sobre as características de carcaça. O rendimento verdadeiro médio de carcaça foi de $51,5 \%$ e o rendimento de carcaça comercial, de $42,4 \%$. Não foram observadas diferenças entre as variáveis condição corporal e conformação da carcaça, em função dos tratamentos. As variáveis cobertura de gordura, cor da gordura e espessura de gordura foram semelhantes. As formas dos grãos de milho utilizados na alimentação dos cordeiros não causaram efeitos sobre a carcaça, considerando-se as variáveis quantitativas e qualitativas.
\end{abstract}

Palavras-chave: característica de carcaça, ovinos, rendimento de carcaça, silagem de grãos.

\section{Characteristics of the Carcass of Lambs Fed Diets with Corn Grains Conserved in Different Forms}

\begin{abstract}
The objective of this study was to evaluate the use of corn grains in different forms (corn dry grain, high moisture corn silage, moisturized corn silage) in the diet of confined lambs, and its possible effects on the qualitative and quantitative characteristics of the carcass. Twenty male Bergamacia x Corriedade lambs were used. The animals were confined and fed ad libitum, assigned to five treatments consisted of dry corn: high moisture corn silage or moisturized corn silage (0:100, 50:50, 100:0). There was not effect of the treatments on the main carcass characteristics. The average true yield of carcass was $51.5 \%$, while the yield of commercial carcass was 42.4\%. Differences were not observed between the variable body condition and conformation of the carcass, in function of the treatments. The variables fat covering, fat color and fat thickness were similar. The forms of the corn grains used in the feeding of the lambs did not affect the qualitative and quantitative characteristics of the carcass.
\end{abstract}

Key Words: carcass characteristic, carcass yield, high moisture corn, lambs

\section{Introdução}

A ovinocultura no Brasil encontra-se em desenvolvimento nos Estados de São Paulo, Paraná, Mato Grosso do Sul e Santa Catarina, sendo a carne ovina considerada uma excelente fonte de proteína de alto valor biológico. No Rio Grande do Sul, ênfase já foi dada à produção de lã, porém o potencial desta espécie na produção de carne é uma de suas particularidades; com algumas raças apresentando alta eficiência para ganho de peso e qualidade de carcaça. Atualmente, o enfoque da atividade no Rio Grande do Sul está voltado para a produção de carne, principalmente em função da atual desvalorização da lã.

Uma das peculiaridades da espécie ovina é apresentar alta eficiência para ganho de peso e qualidade da carcaça, nos primeiros seis meses de vida, somando-se, ainda, o rápido ciclo reprodutivo, pois com oito meses, incluindo cinco de gestação, já é possível o abate dos animais.

Em vista disto, a ovinocultura é uma atividade com retorno econômico garantido em vários países, como a Nova Zelândia, Austrália, Uruguai e inúmeros países europeus, conhecidos pelo alto nível de industrialização (FIGUEIRÓ e BENAVIDES, 1990). Essa

\footnotetext{
1 Parte da Dissertação apresentada pelo primeiro Autor à Universidade Estadual de Maringá (UEM) para obtenção do título "Magister Scientiae". 2 Professor do Dep. de Zootecnia da ESAPP - Escola Superior de Agronomia e Zootecnia de Paraguaçu Paulista-SP.

3 Professor do Departamento de Zootecnia - UEM. E.mail: ccjobim@uem.br

* Pesquisador do CNPq.
} 
atividade, desenvolvida inicialmente na região Sul do país, vem aumentando significativamente no Brasil, estimulada principalmente pelo elevado potencial de consumo nos grandes centros urbanos. Porém, a produção e a comercialização da carne de ovinos no Brasil ainda não se encontra organizada. Apresenta baixa oferta, sendo que além disso, a maioria dos produtores não estão conscientizados da necessidade de se produzir carne de boa qualidade, levando ao mercado carcaças de animais com idade avançada, o que vem contribuir para dificultar ainda mais o crescimento do consumo. Tem-se comprovado o crescimento do consumo em algumas regiões que abatem animais jovens, com carcaças apresentadas ao consumidor em cortes especiais (MACEDO, 1998).

Essas características podem ser otimizadas pelo uso de sistemas adequados de cruzamentos e de terminação. Desse modo, a prática de terminação de ovinos em confinamento, ou em pastagens de alta qualidade, possibilitaria disponibilizar ao mercado consumidor um animal mais jovem com características de carcaça favoráveis, o que contribuiria com certeza para expansão do consumo.

O sistema de comercialização habitual, a exemplo do que ocorre em bovinos, é feito em função do peso vivo, não sendo considerada deste modo a qualidade da carcaça. Com isto ocorre desestímulo pelo criador em produzir animais de melhor qualidade, o que seria possível com o abate de animais jovens.

Segundo MACEDO (1998), a maior valorização das terras próximas aos grandes centros consumidores orienta à adoção de alta tecnologia para produção de carne de cordeiros. Desse modo, buscam-se animais que tenham alto potencial genético para ganho de peso e, principalmente, um sistema de terminação eficiente, para obtenção de maior quantidade de carne com qualidade, no menor espaço de tempo, a custos compatíveis.

O confinamento é uma alternativa que conduz a produção de carne de cordeiro com maior rapidez, ao mesmo tempo que facilita o controle da verminose, pois não entram em contato com as pastagens, principal fonte de contaminação dos animais. BORDA et al. (1993) afirmam que, em um rebanho de ovinos, apenas uma pequena parcela da população parasitária, menos de $5 \%$, encontra-se dentro dos animais, enquanto o restante, mais de $95 \%$, encontra-se nas pastagens. Além do mais em confinamento é possível produzir carcaças sem resíduos de vermífugos. O confinamento passa a ser uma opção aos ovinocultores de regiões susceptíveis às altas cargas endoparasitárias.
Medidas objetivas e subjetivas poderão ser utilizadas a fim de se avaliar as condições de uma carcaça, de maneira que podemos encontrar características diferentes dentro de uma espécie animal. Para COLOMER-ROCHER (1992) as carcaças de mesmo peso que apresentarem maior proporção de músculo e menor de gordura, originam-se de raças com aptidão para produção de carne, de morfologia compacta, sendo que carcaças bem conformadas causam melhor impressão aos consumidores. FARIAS et al. (1986) afirmam que a conformação permite avaliar, principalmente, o desenvolvimento muscular da carcaça.

A alimentação animal tem se tornado um assunto de alta prioridade, face às relações desfavoráveis entre os custos dos insumos, principalmente concentrados. Diante disso, deve-se buscar a utilização de tecnologias que permitam eficiência e economicidade em qualquer exploração pecuária. Nesse sentido, o uso de silagem de grãos úmidos de milho pode constituir-se em importante alternativa do uso desse cereal.

O uso desta tecnologia traz inúmeras vantagens, permitindo, por exemplo, antecipação da colheita, liberando terra para outras culturas; utilização de um sistema de armazenamento mais simples e econômico, evitando o ataque de roedores e carunchos nos grãos, diminuindo deste modo as perdas a campo; e conservação do valor nutritivo por um maior período de tempo.

De acordo com SANTOS (1992) e JOBIM et al. (1997), além das perdas quantitativas, são bastante acentuadas as referentes à qualidade dos grãos. Assim, além da silagem de grãos como opção para minimizar estas perdas, também existe a possibilidade de utilização dos grãos de milho hidratados e ensilados. Esta opção, por sua vez, permite a utilização do grão seco, que após a elevação de sua umidade, permite o processo de ensilagem, trazendo dessa forma alternativas de armazenamento com perdas reduzidas. Este estudo foi conduzido com o objetivo principal de avaliar o uso de grãos de milho em diferentes formas (grãos secos, silagem de grãos úmidos, grãos hidratados e ensilados), na dieta de cordeiros confinados, e seus possíveis efeitos sobre a qualidade da carcaça.

\section{Material e Métodos}

O experimento foi conduzido na Universidade Estadual de Maringá-UEM, no Câmpus do Arenito, localizado no Município de Cidade Gaúcha - PR. Foram utilizados 20 cordeiros machos cruza Bergamácia x Corriedale, desmamados com 50 dias de idade. Entre o 3 o e 5 dia de vida todos foram 
1310 Rev. bras. zootec.

caudectomizados, e com 15 dias foram vacinados contra ectima contagioso e aos 45 dias receberam vacina contra carbúnculo, gangrena gasosa e enterotoxemia.

Os tratamentos constaram de concentrado formulado com grãos de milho conservados em diferentes formas como segue: grãos de milho secos: silagem de grãos úmidos ou silagem de milho hidratado (0:100, 50:50, 100:0). A composição química dos alimentos utilizados nesse estudo está apresentada na Tabela 1.

Os animais foram alojados em instalação com piso ripado suspenso, onde receberam ad libitum ração completa, constituída de feno de aveia (Avena strigosa Schereb) como volumoso mais ração concentrada (Tabela 2).

Para a confecção da silagem de grãos úmidos de milho a colheita foi efetuada na fase de maturação fisiológica, ocasião em que os grãos apresentavam em torno de $70 \%$ de MS, o que na prática é verificado quando um quarto do grão está mole e o resto farináceo. O milho foi colhido manualmente, debulhado em trilhadeira estacionária ligada a tomada de potência do trator, e a seguir triturado em desintegrador de grãos e ensilado em silo trincheira.

Para o processo de ensilagem dos grãos de milho hidratados, procedeu-se primeiramente à moagem do milho em desintegrador de grãos, produzindo o que é conhecido na prática como milho moído grosso. Realizada a hidratação, na proporção de 65 litros de água para cada $100 \mathrm{~kg}$ de milho, procedeu-se à ensilagem em silo trincheira revestido com lona plástica, sendo compactado a medida que o silo ia sendo carregado. Após enérgica compactação $\left(850 \mathrm{~kg} / \mathrm{m}^{3}\right)$, o silo foi vedado com lona plástica, permanecendo fechado por 45 dias.

Os animais, em todos tratamentos, apresentaram diferentes pesos na origem $(28,32,36$ e $40 \mathrm{~kg})$, após permanecerem por 18 horas em dieta hídrica, exclusivamente. Previamente ao abate, determinou-se a condição corporal (CC), por meio da palpação da região lombar, conferindo-se nota de 1,00 a 5,00 (1,00 para pior e 5,00 para a melhor).

Ao abate, os animais foram novamente pesados (peso vivo ao abate) para determinação da perda de peso da origem ao abate. Após o sacrifício, o aparelho gastrointestinal foi esvaziado para obtenção do peso vivo vazio ( $\mathrm{PVV}=$ peso vivo ao abate menos o peso do conteúdo gastrointestinal), visando determinar o rendimento verdadeiro (RV), que é a relação entre o peso da carcaça quente e aquela variável (SAÑUDO e SIERRA, 1986). Terminada a evisceração, pesaram-se as carcaças (peso da car-

Tabela 1 - Composição química dos alimentos utilizados nos tratamentos (\% da MS)

Table 1 - Chemical composition of feeds used in the treatment (\% of DM)

\begin{tabular}{|c|c|c|c|c|c|}
\hline & $\begin{array}{l}\text { Feno de } \\
\text { aveia } \\
\text { Oats hay }\end{array}$ & $\begin{array}{l}\text { Grão milho } \\
\text { moído } \\
\text { Corn ground } \\
\text { grain }\end{array}$ & $\begin{array}{l}\text { Soja integral } \\
\text { moída } \\
\text { Soy whole } \\
\text { ground }\end{array}$ & $\begin{array}{l}\text { Silagem grão } \\
\text { umido } \\
\text { High moisture } \\
\text { corn }\end{array}$ & $\begin{array}{l}\text { Silagem grão } \\
\text { hidratado } \\
\text { Moisturized corn } \\
\text { silage }\end{array}$ \\
\hline $\begin{array}{l}\mathrm{FDN}(\%) \\
N D F(\%)\end{array}$ & 60,6 & 13,16 & 14,3 & 14,2 & 13,27 \\
\hline FDA $(\%)$ & 32,70 & 2,2 & 9,9 & 2,5 & 1,99 \\
\hline $\begin{array}{l}\mathrm{PB}(\%) \\
C P(\%)\end{array}$ & 11,4 & 10,70 & 47,6 & 10,2 & 6,9 \\
\hline $\begin{array}{l}\mathrm{EE}(\%) \\
\mathrm{pH} \\
\mathrm{MS}(\%)\end{array}$ & $\begin{array}{l}--- \\
--- \\
85.4\end{array}$ & $\begin{array}{c}3,72 \\
--- \\
87,91\end{array}$ & $\begin{array}{c}2,2 \\
-919\end{array}$ & $\begin{array}{c}4,8 \\
3,5 \\
667\end{array}$ & $\begin{array}{c}4,05 \\
3,7 \\
89,97\end{array}$ \\
\hline $\begin{array}{l}\mathrm{MS}(\%) \\
D M(\%)\end{array}$ & & & & & \\
\hline $\begin{array}{l}\mathrm{MO}(\%) \\
O M\end{array}$ & ---- & ---- & 94,4 & 99,1 & 98 \\
\hline $\begin{array}{l}\mathrm{EB}(\mathrm{kcal} / \mathrm{kg}) \\
G E(k c a l / k g)\end{array}$ & ---- & 4640 & 4531 & 4330 & 4580 \\
\hline $\begin{array}{l}\text { Amido }(\%) \\
\text { Starch }(\%)\end{array}$ & ---- & 88,72 & ---- & 80,59 & 83,28 \\
\hline
\end{tabular}

FDN = fibra em detergente neutro; FDA = fibra em detergente ácido; $P B$ = proteína bruta; $E E$ = extrato etéreo; $M S$ = matéria seca; $M O$ = matéria orgânica; $\mathrm{EB}$ = energia bruta.

$N D F=$ neutral detergent fiber; $A D F=$ acid detergent fiber; $C P=$ crude protein; $E E=$ ether extract, $D M=$ dry matter; $O M=$ organic matter; $G E=$ gross energy. 
caça quente - PCQ), transferindo-as para uma câmara frigorífica a $4^{\circ} \mathrm{C}$, onde permaneceram por 24 horas, penduradas pelos tendões em ganchos apropriados para manutenção das articulações tarso metatarsianas distanciadas em $17 \mathrm{~cm}$. Ao final desse período, pesou-se a carcaça fria, calculandose então a porcentagem de perda de peso por resfriamento e o rendimento comercial (relação entre o peso da carcaça fria e o peso vivo ao abate).

As carcaças foram avaliadas visualmente, segundo metodologia citada por COLOMER-ROCHER (1988), para as seguintes características: Grau de Conformação (GC), considerando a carcaça como um todo, dando ênfase às diferentes regiões anatômicas: perna, garupa, lombo e escápula, bem como à espessura de seus planos musculares e adiposos, em relação ao esqueleto que a suporta, atribuindo-se 1,00 para muito pobre e 5,00 para excelente; Cobertura de Gordura (CBG), sendo 1,00 para excessivamente magra e 5,00 para excessivamente gorda. Para cor da gordura, consistência da gordura e cor da carne, utilizou-se a escala de 1,00 a 3,00 pontos, sendo cor da gordura (CG), (1,00 para branca e 3,00 amarela); consis-

Tabela 2 - Composição percentual das dietas utilizadas na avaliação de desempenho e qualidade de carcaça dos cordeiros

Table 2 - Percentage composition of the diets used in the evaluation and quality of lambs carcass

\begin{tabular}{llllll}
\hline & T1 & T2 & T3 & T4 & T5 \\
\hline GMS & ---- & 24,2 & 11,4 & ---- & 11,6 \\
GDC & & & & & \\
SGMH & 30,15 & ---- & 15,5 & ---- & ---- \\
SGMD & & & & & \\
SGMU & ---- & ---- & --- & 28,89 & 15,54 \\
SGHC & & & & & \\
FSJ & 35,5 & 36,35 & 35,1 & 33,19 & 34,50 \\
SM & & & & & \\
FAV & 35,35 & 38,45 & 37,0 & 36,91 & 38,36 \\
HO & 1,00 & 1,00 & 1,00 & 1,00 & 1,00 \\
CAL & & & & & \\
CAL & & & & & \\
\hline
\end{tabular}

GMS (grão de milho seco); SGMH (silagem grão de milho hidratado); SGMU (silagem grão de milho úmido); FSJ (farelo de soja); FAV (feno de aveia); CAL (calcário).

$\mathrm{T} 1$ = silagem de milho hidratado:grão de milho seco (100:0); $\mathrm{T} 2$ = silagem de grãos úmidos:grão de milho seco $(0: 100)$; T3 = silagem de milho hidratado:grão de milho seco (50:50); T4 = silagem de grãos úmidos:grãos de milho seco (100:0); T5 = milho úmido:grão de milho seco (50:50).

CGD (corn grain dry); MCS (moisturized corn silage); HMCS (high moisture corn silage); SM(soybean meal); $H O$ (oats hay); CAL (limestone).

$T 1=$ moisturized corn grain silage: dry corn grain (100:0); T2 = high moisture corn silage: dry corn grain (0:100); T3 = moisturized corn silage: corn grain dry (50:50); T4 = high moisture corn silage: corn grain dry (100:0); T5 = high moisture corn silagem: corn grain dry $(50: 50)$. tência da gordura (COG) (1,00 para firme e 3,00 mole) e cor da carne (CC), (1,00 para rosa e 3,00 roxa). Todas as notas referentes à avaliação subjetiva foram fracionadas em 0,25 .

No longissimus dorsi tomou-se a área transversal em transparência e, posteriormente, através do programa computacional AUTOCAD, foi determinada a área de olho de lombo. Ainda no longissimus dorsi, utilizando-se paquímetro, foi medida a espessura de gordura de cobertura sobre a secção do mesmo (entre a última vértebra dorsal e primeira lombar).

Para cálculo dos índices de compacidade, realizaram-se as seguintes mensurações, segundo SAÑUDO e SIERRA (1986) e MACEDO (1998): comprimento da perna (distância entre o períneo e o bordo anterior da superfície articular tarso metatarsiana), largura da garupa (largura máxima entre os trocânteres de ambos os fêmures, tomada com compasso), comprimento interno da carcaça (distância máxima entre o bordo anterior da sínfese isquio-pubiana e o bordo anterior da primeira costela em seu ponto médio). Foram calculados os índices de compacidade da carcaça (peso da carcaça fria dividido pelo comprimento interno da carcaça) e de compacidade da perna (largura da garupa dividida pelo comprimento da perna). Posteriormente, a carcaça foi seccionada ao meio e a metade esquerda foi pesada e subdividida em 7 regiões anatômicas, as quais foram pesadas individualmente, determinando-se posteriormente as porcentagens que representavam em relação ao todo: Pescoço (compreende a região anatômica das sete vértebras cervicais, sendo obtida através de um corte oblíquo que passa entre a sétima vértebra cervical e a primeira torácica, buscando a ponta do esterno e terminando no bordo interior do pescoço); Paleta (região que tem como base anatômica a escápula, úmero, ulna, rádio e carpo); Costelas descobertas (apresentam como base óssea as cinco primeiras vértebras dorsais, junto com a metade superior do corpo das costelas correspondentes); Costelas (são as oito últimas vértebras dorsais, juntamente com a metade superior das costelas correspondentes); Baixos (obteve-se traçando uma linha reta da borda dorsal do abdômen à ponta do esterno); Lombo (tem como base anatômica as vértebras lombares, sendo a zona que incide perpendicularmente com a coluna, entre a $13^{\mathrm{a}}$ vértebra dorsal e a última lombar); Perna (conjunto que compreende as regiões glútea femural e da perna, tendo como base óssea, o tarso, a tíbia, o fêmur, ísquio, púbis e ílio, separado por um corte 
1312 Rev. bras. zootec.

perpendicular à coluna, entre as duas últimas vértebras lombares). As regiões foram agrupadas em cortes anatômicos de primeira (pernil e lombo), segunda (paleta e costelas) e terceira (costela descoberta, baixos e pescoço).

Os tratamentos foram arranjados em delineamento experimental inteiramente casualizado com quatro repetições e analisados segundo o modelo $\mathrm{Y}_{\mathrm{ij}}=\mathrm{m}+\mathrm{T}_{\mathrm{i}}+\mathrm{b}\left(\mathrm{PV}_{\mathrm{ij}}-\mathrm{PV}\right)+\mathrm{e}_{\mathrm{ij}}$, em que: $\mathrm{Y}_{\mathrm{ij}}=$ observação referente ao animal $\mathrm{j}$ recebendo o tratamento $\mathrm{i} ; \mathrm{m}=$ constante geral; $\mathrm{T}_{\mathrm{i}}=$ efeito do tratamento $\mathrm{i}, \mathrm{i}=1, \ldots, 5 ; \mathrm{b}=$ coeficiente linear de regressão da variável $\mathrm{Y}$ em função do peso vivo; $\mathrm{PV}_{\mathrm{ij}}=$ peso vivo ao abate do animal $\mathrm{j}$ do tratamento $\mathrm{i} ; \mathrm{PV}=$ peso vivo médio dos animais ao abate; $\mathrm{e}_{\mathrm{ij}}=$ erro aleatório associado a cada observação.

\section{Resultados e Discussão}

Não houve efeito dos tratamentos sobre as características das carcaças estudadas (Tabela 3). Com relação aos pesos de carcaça quente e de carcaça fria, não foram evidenciados efeitos das formas de conservação dos grãos de milho empregados nos concentrados, com pesos médios de 14,52 kg e 14,13 $\mathrm{kg}$, respectivamente. A perda de peso por resfriamento (PPR) foi em média de $2,72 \%$, valores considerados normais de acordo com a literatura consultada (BONIFÁCIO et al.,1979); FIGUEIRÓ, 1979; CARVALHO et al.,1980; SILVEIRA et al.,1980), estando dentro da faixa aceitável $(3,0-4,0 \%)$ segundo SAÑUDO e SIERRA (1981).

Nota-se pelos resultados apresentados na Tabela 3 , que os rendimentos verdadeiro, comercial e perda na origem, não foram afetados pelos tratamentos. O RVC médio, considerando-se todos os tratamentos, foi de $51,50 \%$; o RCC, de $42,40 \%$; e perda na origem, de $4,54 \%$. Esses valores podem ser considerados bons, sendo equivalentes àqueles registrados por MACEDO (1998). Os rendimentos verdadeiro e comercial são equivalentes àqueles apresentados por outros autores, em estudos com cordeiros (LATIF e OWEN (1980), SAÑUDO et al. (1981), SAÑUDO e SIERRA (1986), GUNEY (1989), MARTINS (1997)

Tabela 3 - Médias para peso na origem (PO), no abate (PA), perda de peso da origem ao abate (PPO), peso da carcaça quente (PCQ), peso da carcaça fria (PCF), perda de peso por resfriamento (PPR), rendimento de origem (RO), rendimento verdadeiro (RVC), rendimento comercial (RCC), índice de compacidade da carcaça (ICC) e índice de compacidade do pernil (ICP), conforme o tratamento

Table 3 - Averages for weight in the origin (WO), in the discount (WD) and percentage of losses (PWL), hot carcass weight (HCW), cold carcass weight (CCW), weight loss for cooling (WLC), origin revenue (OR), true revenue (TR), commercial revenue (CR), index of compactness of the carcass (ICC) and index of compactness of the leg (ICL), according to treatment

\begin{tabular}{|c|c|c|c|c|c|c|}
\hline $\begin{array}{l}\text { Variável } \\
\text { Variable }\end{array}$ & $\mathrm{T} 1$ & $\mathrm{~T} 2$ & T3 & $\mathrm{T} 4$ & $\mathrm{~T} 5$ & $\begin{array}{l}\text { Média } \\
\text { Average }\end{array}$ \\
\hline $\begin{array}{l}\mathrm{PO}(\mathrm{kg}) \\
W O(k g)\end{array}$ & 34,00 & 34,20 & 32,40 & 34,80 & 36,15 & 34,31 \\
\hline $\begin{array}{l}\mathrm{PA}(\mathrm{kg}) \\
W D(k g)\end{array}$ & 31,90 & 33,40 & 30,67 & 33,38 & 34,42 & 32,75 \\
\hline $\begin{array}{l}\text { PPO (\%) } \\
P W L(\%)\end{array}$ & 6,17 & 2,34 & 5,34 & 4,08 & 4,78 & 4,57 \\
\hline $\begin{array}{l}\mathrm{PCQ}(\mathrm{kg}) \\
H C W(k g)\end{array}$ & 14,37 & 14,18 & 14,66 & 14,27 & 15,13 & 14,52 \\
\hline $\begin{array}{l}\mathrm{PCF}(\mathrm{kg}) \\
C C W(\mathrm{~kg})\end{array}$ & 13,97 & 13,75 & 14,26 & 13,89 & 14,78 & 14,13 \\
\hline $\begin{array}{l}\operatorname{PPR}(\%) \\
W L C(\%)\end{array}$ & 2,82 & 3,04 & 2,7 & 2,70 & 2,32 & 2,72 \\
\hline $\begin{array}{l}\mathrm{RVC}(\%) \\
\operatorname{TR}(\%)\end{array}$ & 52,48 & 51,09 & 50,73 & 51,36 & 51,85 & 51,50 \\
\hline $\begin{array}{l}\mathrm{RCC}(\%) \\
C R(\%)\end{array}$ & 43,76 & 41,01 & 42,59 & 41,72 & 42,90 & 42,40 \\
\hline $\begin{array}{l}\operatorname{ICC}(\mathrm{kg} / \mathrm{cm}) \\
\operatorname{ICC}(\mathrm{kg} / \mathrm{cm})\end{array}$ & 0,216 & 0,207 & 0,213 & 0,198 & 0,212 & 0,209 \\
\hline $\begin{array}{l}\mathrm{ICP} \\
\mathrm{ICH}\end{array}$ & 45,86 & 45,86 & 44,75 & 45,53 & 46,75 & 45,75 \\
\hline
\end{tabular}


e MACEDO (1998). Não se observaram diferenças nos índices de compacidade da carcaça entre os tratamentos, sendo que os valores obtidos se encontram próximos aos citados por SAÑUDO et al. (1981), que é de 201,84. Porém, as carcaças mais pesadas apresentaram maior $(\mathrm{P}<0,05)$ índice de compacidade, o que é corroborado por OSÓRIO (1992), segundo o qual carcaças de melhor conformação subjetiva são as mais curtas.

Não foram observadas diferenças $(\mathrm{P}>0,05)$ entre as variáveis Condição Corporal (CC) e Conformação (CO), em função dos tratamentos (Tabela 4). As variáveis Cobertura de Gordura (CBG), Cor da Gordura (CG) foram semelhantes, com valores para coloração da gordura equivalentes aos apresentados por JONES et al. (1984). Com relação aos valores consta-

Tabela 4 - Médias para condição corporal (CC), conformação (CO), cobertura de gordura (CBG), cor da gordura (CG), cor da carne (CCA), consistência da gordura (COG), área de olho de lombo (AOL) e espessura de gordura (EG), de cordeiros

Table 4 - Averages for corporal condition (CC), conformation (CO), fat covering (FC), fat color (CF), meat color (CM), fat consistency (CNF), loin eye area (LEA) and fat thickness (FT) of lambs

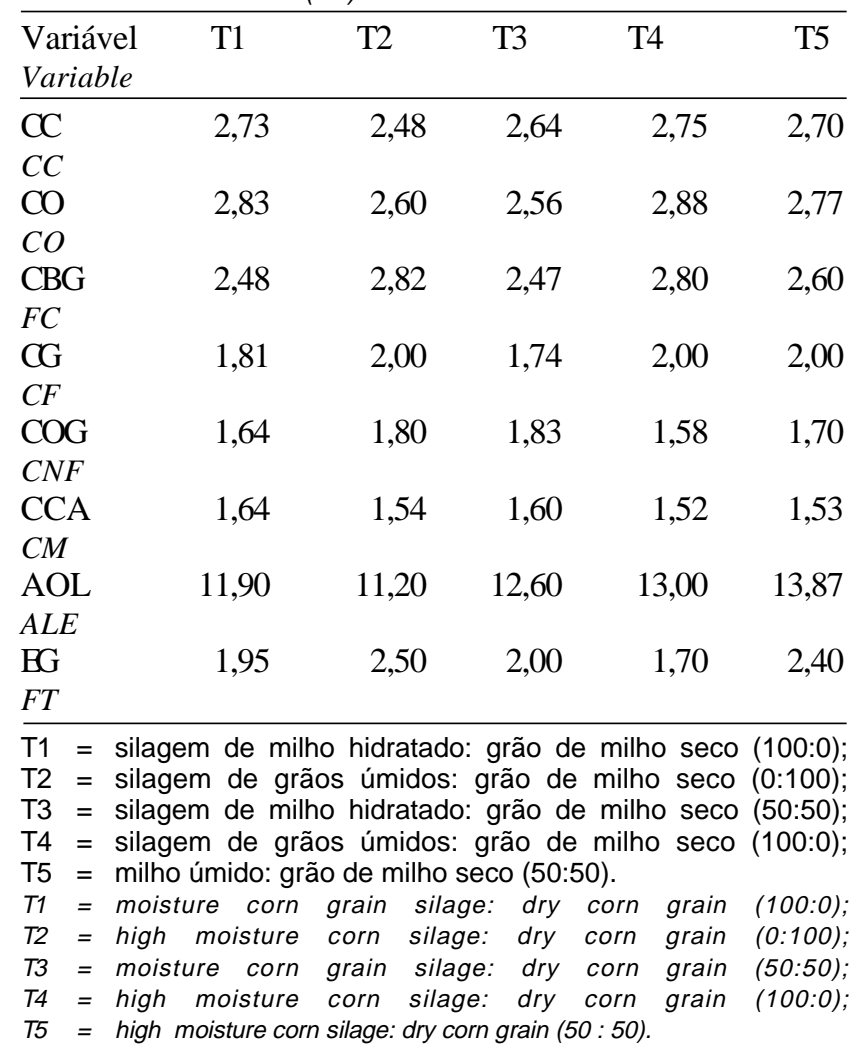

tados para cobertura de gordura, não houve diferenças $(\mathrm{P}>0,05)$ entre as dietas avaliadas. Entretanto, constatou-se que maior peso ao abate (Tabela 3 ) proporciona maior cobertura de gordura na carcaça. As médias para Área de Olho de Lombo (AOL) e Espessura de Gordura (EG), de acordo com os tratamentos, encontram-se na Tabela 4. Constatou-se que não houve efeito dos tratamentos sobre o parâmetro AOL, ressaltando-se que os valores obtidos são compatíveis com carcaças de alta qualidade de acordo com JONES et al. (1984) e MACEDO (1998). Não houve efeito de tratamento sobre espessura de gordura; entretanto, constatouse que, à medida que o peso vivo aumenta, elevase a medida desta variável, ressaltando-se, porém, os excelentes níveis de tecido adiposo nestas carcaças (média de 2,11), estando de acordo com JONES et al. (1984).

A cor da carne foi semelhante para todos os tratamentos, apresentando-se mais próxima da cor rosa (média 1,56), concordando com JONES et al. (1984). No entanto, a análise de variância (Tabela 6) aponta alteração na cor da carne em relação ao peso vivo, em que maior peso do animal ao abate resultou em carne mais escura.

Na Tabela 5, são apresentados os valores referentes aos pesos e rendimentos dos cortes.

$\mathrm{Na}$ Tabela 5, são apresentados os dados referentes arendimentode pescoço, em que, pela análise de variância, observa-se tendência de aumento neste percentual com a evolução do peso vivo, o que vem concordar com os resultados obtidos por SAÑUDO et al. (1992) e SOUSA (1993). As demais variáveis, em relação a rendimento dos cortes, não apresentaram diferenças significativas em relação aos tratamentos utilizados.

Os RPE, RPA, RC e RL foram semelhantes aos registrados por COLOMER-ROCHER e ESPEJO (1972), que trabalharam com cordeiros mestiços Manchega x Aragonesa, abatidos ao redor de $30 \mathrm{~kg}$. O mesmo ainda foi verificado em trabalhos efetuados por outros autores (SIERRA, 1970; BONIFÁCIO et al., 1979; SILVEIRA et al., 1980; e SIQUEIRA, 1983). De acordo com CAÑEQUE et al. (1989), somente têm-se encontrado pequenas diferenças no peso dos cortes das carcaças de diferentes conformações. Resultados de pesquisa revelam que carcaças de melhor conformação apresentam mesmos pesos e cortes que as demais, mostrando, assim, que essa diferença na conformação, sob o ponto de vista prático, é desprezível. 
1314 Rev. bras. zootec.

Tabela 5 - Médias para pesos e rendimentos da perna (PPE e RPE), da paleta (PPA e RPA), do lombo (PL e RL), da costela (PC e RC), da costela descoberta (PCD e RCD), dos baixos (PB e RB) e do pescoço (PP e RP), conforme os tratamentos

Table 5 - Averages for weights and revenues of the leg (WL and RL), shoulder (WS and RS), loin (WL and RL), rib (WR and RR), discovered rib (WDR and RDR), bass (WB and RB) and neck (WN and RN), according to the treatments

\begin{tabular}{|c|c|c|c|c|c|}
\hline $\begin{array}{l}\text { Variável } \\
\text { Variable }\end{array}$ & $\mathrm{T} 1$ & $\mathrm{~T} 2$ & $\mathrm{~T} 3$ & $\mathrm{~T} 4$ & T5 \\
\hline & \multicolumn{5}{|c|}{$\begin{array}{l}\text { Cortes de primeira } \\
\text { Cuts of first }\end{array}$} \\
\hline PPE $(\mathrm{kg})$ & 2,397 & 2,116 & 2,260 & 2,380 & 2,530 \\
\hline $\begin{array}{l}W H(\mathrm{~kg}) \\
\mathrm{RPE}(\%) \\
R H(\%)\end{array}$ & 35,29 & 31,80 & 32,72 & 34,34 & 34,64 \\
\hline $\begin{array}{l}\mathrm{PL}(\mathrm{kg}) \\
W L(\mathrm{~kg})\end{array}$ & 0,634 & 0,640 & 0,584 & 0,660 & 0,700 \\
\hline \multicolumn{5}{|l|}{$R L(\%)$} & 9,60 \\
\hline & \multicolumn{5}{|c|}{$\begin{array}{l}\text { Cortes de segunda } \\
\text { Cuts of second }\end{array}$} \\
\hline $\begin{array}{l}\mathrm{PPA}(\mathrm{kg}) \\
W P(k g)\end{array}$ & 1,346 & 1,250 & 1,623 & 1,240 & 1,265 \\
\hline $\begin{array}{l}\text { RPA }(\%) \\
R P(\%)\end{array}$ & 19,82 & 18,78 & 23,50 & 17,89 & 17,31 \\
\hline $\begin{array}{l}\mathrm{PC}(\mathrm{kg}) \\
W R(k g)\end{array}$ & 0,550 & 0,615 & 0,634 & 0,580 & 0,620 \\
\hline $\begin{array}{l}\mathrm{RC}(\%) \\
R R(\%)\end{array}$ & 8,10 & 9,24 & 9,20 & 8,36 & 8,48 \\
\hline & \multicolumn{5}{|c|}{$\begin{array}{l}\text { Cortes de terceira } \\
\text { Cuts of third }\end{array}$} \\
\hline $\begin{array}{l}\mathrm{PCD}(\mathrm{kg}) \\
W D R(k g)\end{array}$ & 0,825 & 0,889 & 0,734 & 0,810 & 0,890 \\
\hline $\begin{array}{l}\mathrm{RCD}(\%) \\
R D R(\%)\end{array}$ & 12,15 & 13,36 & 10,63 & 11,70 & 12,80 \\
\hline $\begin{array}{l}\mathrm{PB}(\mathrm{kg}) \\
W B(k g)\end{array}$ & 0,710 & 0,750 & 0,680 & 0,750 & 0,790 \\
\hline $\begin{array}{l}\mathrm{RB}(\%) \\
R B(\%)\end{array}$ & 10,45 & 11,26 & 9,85 & 10,83 & 10,81 \\
\hline $\begin{array}{l}\mathrm{PP}(\mathrm{kg}) \\
W N(k g)\end{array}$ & 0,330 & 0,395 & 0,390 & 0,510 & 0,510 \\
\hline $\begin{array}{l}\mathrm{RP}(\%) \\
R N(\%)\end{array}$ & 4,86 & 5,94 & 5,65 & 7,36 & 6,98 \\
\hline
\end{tabular}

T1= silagem de milho hidratado: grão de milho seco (100:0); T2 = silagem de grãos úmidos: grão de milho seco (0:100); T3= silagem de milho hidratado: grão de milho seco (50:50); T4 = silagem de grãos úmidos :grãos de milho seco (100:0); T5 = milho úmido: grão de milho seco (50:50).

$T 1=$ moisturized corn grain silage: corn grain dry (100:0); T2 = high moisture corn silages: corn grain dry (0:100); T3 = moisturized corn grain silagem:corn grain dry (50:50); T4 = high moisture corn silage : corn grain dry (100:0); T5 = high moisture corn silage : corn grain dry (50:50).

\section{Conclusões}

As formas dos grãos de milho utilizados na alimentação dos cordeiros não afetaram as variáveis quantitativas e qualitativas estando os valores observados relacionados a carcaças de qualidade elevada.

O peso da carcaça afetou parâmetros como índice de compacidade, cobertura de gordura, espessura de gordura, cor da carne e rendimento do pescoço, concluindo-se que estas variáveis apresentam valores mais elevados quanto maior for o peso ao abate.

A utilização de silagens de grãos úmidos de milho ou de grãos hidratados, em substituição ao grão de milho seco, pode ser utilizada sem restrições na alimentação de cordeiros para produção de carne, sem prejuízo à qualidade da carcaça. 


\section{Referências Bilbiográficas}

BONIFÁCIO, L., KREMER, R., ORLANDO, D. 1979. Estudio comparativo de corderos Corriedale y Corriedale por Texel. 2. Pesos al nacer, ganancias diarias y caracteristicas de la carcasa. Rev. Vet., 70:63-71.

BORBA, M.F.S., MORAES, J.C.F., SILVEIRA, V.C.P. Aspectos relativos a produção de carne ovina. In: SIMPÓSIO PARANAENSE DE OVINOCULTURA, 6, 1993, Maringá. Anais... Maringá, 1993. p.15-26.

CAÑEQUE, V., HUILDOBRO, F.R., DOLZ, J.F. et al. 1989. Producción de Carne de Cordero. Madrid: Ministério de Agricultura Pesca y Alimentación. 520p.

CARVALHO, J.B.D., PEDROSO, J.R., FIGUEIRÓ, P.R.P. 1980. Alguns fatores que afetam o rendimento de carne ovina. Rev. Cent. Ciênc. Rurais, 10(2):95-104.

COLOMER-ROCHER, F., ESPEJO, M.D. 1972. Influencia del peso al sacrificio y del sexo sobre las características de las canales de cordero de raza Rasa Aragonesa. INIA, Serie Producción Animal, (4):133-50.

COLOMER-ROCHER, F. Estudio de los parametros que definem los caracteres cuantitativos y cualitativos de los canales. In: CURSO INTERNACIONAL SOBRE PRODUCIÓN DE CARNE Y LECHE COM BASES EN PASTOS Y FORRAJES. La Coruña, Espanha, 1988. 108p.

COLOMER-ROCHER, F. El carácter conformación en los bovinos y sus determinantes biológicos. In: JORNADAS SOBRE TECNOLOGIA DE VALORACION DE CANALES Y DEFENSA DE LA CALIDAD DE LOS PRODUCTOS GANADEROS, 1982, Zaragoza. Trabalhos apresentados... Zaragoza: Centro Mediterrâneo, Instituto Agronômico Mediterraneo de Zaragoza, 1992. p.1-47.

FARIAS, J.V.S., JARDIM, P.O.C., GUERREIR, J.L.V. Avaliação de carne de novilhos Hereford. 2. Comparação do peso de carcaça e conformação como estimadores. In: REUNIÃO ANUAL DA SOCIEDADE BRASILEIRA DE ZOOTECNIA, 23, 1986, Campo Grande. Anais... Campo Grande: SBZ, 1986.

FIGUEIRÓ, P.R.P. Rendimento de carcaça em ovinos no RS. In: JORNADA TÉCNICA DE PRODUÇÃO OVINA NO RS, 1, 1979, Bagé. Trabalhos apresentados... Bagé, 1979. p.65.

FIGUEIRÓ, P.R.P., BENAVIDES, M.V. Produção de carne ovina. In: CAPRINOCULTURA E OVINOCULTURA. 1990, Piracicaba. Anais... Campinas, SBZ, 1990. p.15-32.

GÜNEY, O. A commercial crossbreeding experiment between Ile de France, Rambouillet, Chios and the local fat Awassi for lamb production. Proccedings, World Congress on Sheep and Beef Cattle Breeding, 3, v.1, n.19-23, 1988. In: Anim. Breed. Abstr., v. 57, p.29, 1989. (Abstract).

JOBIM, C.C., REIS, R.A., RODRIGUES, L.R.A. 1997. Avaliação da silagem de grãos úmidos de milho (Zea mays L.). Pesq. Agropec. Bras., 32(3):311-31.

JONES, S.D.M., BURGESS, T.D., DUPACHAK, K. et al. 1984. The growth performance and carcass composition of ram and ewe lambs fed on pasture or in confinement and slaughtered at similar fatness. Can. J. Anim. Sci., 64:631-40.

LATIF, M.G.A., OWEN, E. 1980. Comparison of Texel and Suffolk sired lambs out of Finnish Landrace x Dorset Horn ewe under grazing conditions. J. Agric. Sci., 92:235-39.

MACEDO, F.A.F. Desempenho e características de carcaças de cordeiros Corriedale e mestiços Bergamácia x Corriedale e Hampshire Down $x$ Corriedale, terminados em pastagem e confinamento. Boutcatu, SP: UNESP, 1998. 72p. Tese (Dou-

torado em Zootecnia) - Universidade Estadual Paulista Faculdade de Medicina Veterinária e Zootecnia de Botucatu, 1998.

MARTINS, A.R.V. Utilização de dejetos de suínos em dietas de ovinos em sistema de confinamento. Lavras, UFL, 1997.51p. (Dissertação de Mestrado em Zootecnia) - Universidade Federal de Lavras, 1997.

OSÓRIO, J.C.S. Estudio de la calidad de canales comercializadas en el tipo ternasco segun la procedencia: bases para la mejora de dicha calidad em Brazil. Zaragoza, 1992. 335p. Tese (Doutorado em Veterinária) - Facultad de Veterinaria, Universidad de Zaragoza.

SAÑUDO, C., PIEDRAFITA, J., SIERRA, I. Estudio de la calidad de la canal y de la carne en animales cruzados Romanov por Rasa Aragonesa. 2. Comparación en el tipo comercial ternasco com Rasa en pureza. In: JORNADAS CIENTÍFICAS DE LA SOCIEDAD ESPAÑOLA DE OVINOTECNIA, 7, 1981, Talavera de la Reina. Actas... Zaragoza: 1981. p.483-9.

SAÑUDO, C., SIERRA, I. 1986. Calidad de la canal en la especie ovina. Ovino, 1:127-153.

SAÑUDO, C., SIERRA, I., ALCALDE, M.J. et al. Carcass and meat quality of light and heavy lambs of Rasa Aragonesa, Lacaune and German Merino breeds. In: ANNUAL MEETING OF THE EUROPEAN ASSOCIATION OF ANIMAL PRODUCTION, 1982, Madrid. Proceedings... Madrid, 1992. p.264.

SANTOS, J. P. dos. Controle de pragas de grãos armazenados. In: CONGRESSO NACIONAL DE MILHO E SORGO, 19, 1992, Porto Alegre. Anais... Porto Alegre-RS, 1992. p.191-209.

SIERRA, I.A. 1970. La conformación en el ganado ovino: su influencia en el rendimiento canal y en el despiece. Instituto de Economia y Producciones Ganaderas del Ebro. C.S.I.C. Univers. de Zaragoza, v.5, p.1-4.

SILVEIRA, P.M., OSÓRIO, J.C.S., JARDIM, P.O.C., et al. Efeito da raça sobre o peso vivo e características da carcaça em ovinos. In: REUNIÃO ANUAL DA SOCIEDADE BRASILEIRA DE ZOOTECNIA, 17, 1980, Fortaleza. Anais.. Fortaleza, 1980. p.112.

SIQUEIRA, E.R. Desempenho e características de carcaça de cordeiros machos e fêmeas da raça Ideal e cruzas Texel X Ideal, criados em pastagem nativa. Pelotas, 1983. 130p. Dissertação (Mestrado em Produção Animal)- Faculdade de Agronomia, Universidade Federal de Pelotas, 1983.

SOUSA, O.R.C. Efeito da idade ao abate sobre o rendimento de carcaça e composição física dos principais cortes, em cordeiros da raça Romney Marsh. Pelotas, 1993. 102p. Dissertação (Mestrado em Zootecnia) - Faculdade de Agronomia, Universidade Federal de Pelotas, 1983.

Recebido em: 10/02/00

Aceito em: 19/04/01 